\section{A Modification of the Skyrme Single Particle Potenital and the RMS Radii of Nuclei}

\section{S. E. Massen}

Department of Theoretical Physics, University of Thessaloniki, Thessaloniki 54006, Greece

Z. Naturforsch. 43a, $821-822$ (1988); received May 21, 1988

The Skyrme single particle potential is modified by adding a new term which is taken to be the derivative of the central part of the Skyrme interaction. It is seen that, when this term is added to the original Skyrme interaction, there is a better agreement with experiment regarding the various moments of the charge densities of nuclei with $48 \leq A \leq 208$.

\section{Introduction}

The Hartree Fock method with various Skyrme type interactions has been extensively applied to explain binding energies, RMS radii and charge densities of nuclei $[1,2,3]$. These properties for ${ }^{208} \mathrm{~Pb}$ have also been studied with a new method [4], where the Skyrme single particle potential has been corrected by using a Woods-Saxon shape for the surface region.

A similar method is used in the present work, but the correction of the Skyrme single particle potential for the surface region does not come from a Woods-Saxon shape but from the derivative of the Skyrme interaction. In this way a new parameter is added to the existing Skyrme parameters.

\section{Details of the Method}

The derivation of the Hartee Fock equations for the Skyrme interaction has been discussed by many authors $[1,2,3]$. When calculations are made with the Skyrme type interactions S3 to S6 [2] there are some small deviations in the RMS charge radii and charge densities. If we want to have a better agreement between the theoretical and the experimental RMS radii and charge densities we have to improve the Skyrme interaction (including for example additional terms). Many attempts have been made in this direction $[4-8]$.

In the present method we add a new term in the Skyrme single particle potential which is surface peaked. This term is taken to be the derivative of the central part of the Skyrme single partical potential $U_{\mathrm{q}}(r)[1]$. That is

$$
U_{\mathrm{q}}(r)=t_{\mathrm{s}} \frac{\mathrm{d} U_{\mathrm{q}}(r)}{\mathrm{d} r},
$$

where $t_{\mathrm{s}}$ is a new parameter, the same for neutrons and protons.

With the above type of interaction we tried to fix the new parameter $t_{\mathrm{s}}$ for ${ }^{208} \mathrm{~Pb}$ and ${ }^{48} \mathrm{Ca}$ so that the corresponding RMS charge radii are the experimental ones. For other

Reprint requests to S. E. Massen, Department of Theoretical Physics, University of Thessaloniki, Thessaloniki 54006, Greece. spherical nuclei with $48 \leq A \leq 208$ we could take an interpolation between these two values of $t_{\mathrm{s}}$.

The values of the parameter $t_{\mathrm{s}}$ which have been found in this way for ${ }^{208} \mathrm{~Pb}$ and ${ }^{48} \mathrm{Ca}$ and for the interactions $\mathrm{S} 3$ are $0.056 \mathrm{fm}$ and $0.069 \mathrm{fm}$, respectivelly. The Skyrme interaction with the new term is called MS. From Table 1 we can see that when the RMS charge radii of these two nuclei are fixed to the experimental ones we also have a better agreement for the other moments. The same is true for the charge densities of these two nuclei. These are shown in Fig. 1, where the charge densities of ${ }^{48} \mathrm{Ca}$ and ${ }^{208} \mathrm{~Pb}$ with interactions $\mathrm{S} 3$ and MS3 have been plotted and compared with experiment. Evidently the interaction MS3 gives better agreement with the experimental charge densities than the interaction S3, not only in the surface but also in the interior of these two nuclei.

The values of the parameter $t_{\mathrm{s}}$ for nuclei $48 \leq A \leq 208$ were obtained using the interpolation formula

$$
t_{\mathrm{s}}(A)=\alpha A^{-1 / 3}+\beta A^{-2 / 3},
$$

where the values of the constants $\alpha$ and $\beta$ were found from the fixed values $t_{\mathrm{s}}(48)$ and $t_{\mathrm{s}}(208)$. One could use an other interpolation formula, but the fixed values of $t_{\mathrm{s}}(48)$ and $t_{\mathrm{s}}(208)$ being similar thus makes no great difference.

Having found the values of the parameter $t_{\mathrm{s}}(A)$ in the above described way, we calculated the moments of the charge density, and the Barrett radii, for many nuclei in the region $48 \leq A \leq 208$, using the interactions S3 and MS3. As seen in Table 1 there is in general better agreement with the experimental moments for the MS3 than for the S3 interaction.

Similar results are obtained with the interaction MS6. In this case the values of the parameter $t_{\mathrm{s}}$ for ${ }^{208} \mathrm{~Pb}$ and ${ }^{48} \mathrm{Ca}$ were $0.077 \mathrm{fm}$ and $0.078 \mathrm{fm}$, respectivelly. This means that in this case it is not necessary to use the interpolation formula (2). For the interactions S4 and S5 one has to use a three parameter interpolation formula.

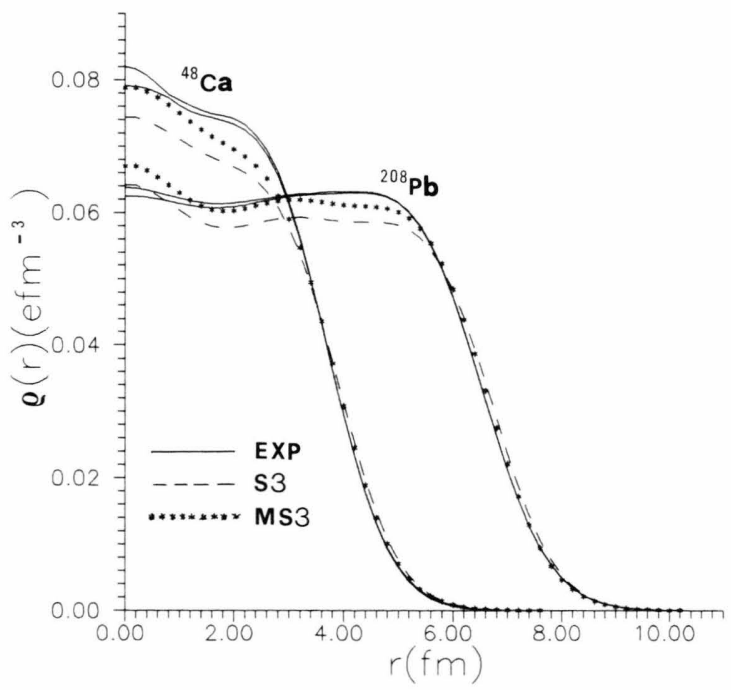

Fig 1. Experimental (EXP) and theoretical charge densities of ${ }^{48} \mathrm{Ca}$ and ${ }^{208} \mathrm{~Pb}$. The theoretical densities were calculated with interactions $\mathrm{S} 3$ and MS3. The experimental curves are from [10 b] for ${ }^{48} \mathrm{Ca}$ and from [11] for ${ }^{208} \mathrm{~Pb}$. 
Table 1. Experimental and theoretical values of moments of the charge distributions of nuclei with $48 \leq A \leq 208$. The theoretical values were obtained with the interactions S3 and MS3.

\begin{tabular}{|c|c|c|c|c|c|c|c|}
\hline & & \multicolumn{3}{|l|}{$\left\langle r^{k}\right\rangle^{1 / k}(\mathrm{fm})$} & \multirow[t]{2}{*}{$k$} & \multirow{2}{*}{$\begin{array}{l}a \\
\left(\mathrm{fm}^{-1}\right)\end{array}$} & \multirow{2}{*}{$\begin{array}{l}\left\langle r^{k} e^{-a r}\right\rangle \\
\left(\mathrm{fm}^{k}\right)\end{array}$} \\
\hline & & $k=2$ & $k=4$ & $k=6$ & & & \\
\hline${ }^{48} \mathrm{Ca}$ & $\begin{array}{l}\text { exp } \\
\text { S3 } \\
\text { MS3 }\end{array}$ & $\begin{array}{l}3.482[9] \\
3.524 \\
3.482\end{array}$ & $\begin{array}{l}3.78[10] \\
3.817 \\
3.779\end{array}$ & $\begin{array}{l}4.05[10] \\
4.071 \\
4.036\end{array}$ & $\begin{array}{l}2.114 \\
2.114 \\
2.114\end{array}$ & $\begin{array}{l}0.065 \\
0.065 \\
0.065\end{array}$ & $\begin{array}{l}10.884 \quad(5)[9] \\
11.172 \\
10.926\end{array}$ \\
\hline${ }^{208} \mathrm{~Pb}$ & $\begin{array}{l}\text { exp } \\
\text { S3 } \\
\text { MS3 }\end{array}$ & $\begin{array}{l}5.503[11] \\
5.574 \\
5.503\end{array}$ & $\begin{array}{l}5.85[11] \\
5.909 \\
5.838\end{array}$ & $\begin{array}{l}6.13[11] \\
6.173 \\
6.102\end{array}$ & $\begin{array}{l}2.323 \\
2.323 \\
2.323\end{array}$ & $\begin{array}{l}0.113 \\
0.113 \\
0.113\end{array}$ & $\begin{array}{l}21.384 \\
27.756 \\
27.171\end{array}$ \\
\hline${ }^{50} \mathrm{Ti}$ & $\begin{array}{l}\text { exp } \\
\text { S3 } \\
\text { MS3 }\end{array}$ & $\begin{array}{l}3.576(4)[9] \\
3.604 \\
3.565\end{array}$ & $\begin{array}{l}3.902 \\
3.867\end{array}$ & $\begin{array}{l}4.163 \\
4.134\end{array}$ & $\begin{array}{l}2.118 \\
2.118 \\
2.118\end{array}$ & $\begin{array}{l}0.068 \\
0.068 \\
0.068\end{array}$ & $\begin{array}{l}11.354 \text { (4) [9] } \\
11.572 \\
11.335\end{array}$ \\
\hline${ }^{52} \mathrm{Cr}$ & $\begin{array}{l}\exp \\
\text { S3 } \\
\text { MS3 }\end{array}$ & $\begin{array}{l}3.645(3)[9] \\
3.675 \\
3.683\end{array}$ & $\begin{array}{l}3.977 \\
3.944\end{array}$ & $\begin{array}{l}4.242 \\
4.218\end{array}$ & $\begin{array}{l}2.115 \\
2.115 \\
2.115\end{array}$ & $\begin{array}{l}0.071 \\
0.071 \\
0.071\end{array}$ & $\begin{array}{l}11.584 \text { (2) [9] } \\
11.804 \\
11.577\end{array}$ \\
\hline${ }^{54} \mathrm{Fe}$ & $\begin{array}{l}\exp \\
\text { S3 } \\
\text { MS3 }\end{array}$ & $\begin{array}{l}3.694(5)[12] \\
3.740 \\
3.704\end{array}$ & $\begin{array}{l}4.044 \\
4.015\end{array}$ & $\begin{array}{l}4.313 \\
4.295\end{array}$ & $\begin{array}{l}2.121 \\
2.121 \\
2.121\end{array}$ & $\begin{array}{l}0.074 \\
0.074 \\
0.074\end{array}$ & $\begin{array}{l}11.856 \text { (4) [13] } \\
12.137 \\
11.919\end{array}$ \\
\hline${ }^{56} \mathrm{Fe}$ & $\begin{array}{l}\exp \\
\text { S3 } \\
\text { MS3 }\end{array}$ & $\begin{array}{l}3.739(5)[12] \\
3.761 \\
3.726\end{array}$ & $\begin{array}{l}4.063 \\
4.032\end{array}$ & $\begin{array}{l}4.327 \\
4.305\end{array}$ & $\begin{array}{l}2.121 \\
2.121 \\
2.121\end{array}$ & $\begin{array}{l}0.074 \\
0.074 \\
0.074\end{array}$ & $\begin{array}{l}12.102(2)[12] \\
12.263 \\
12.048\end{array}$ \\
\hline${ }^{58} \mathrm{Ni}$ & $\begin{array}{l}\text { exp } \\
\text { S3 } \\
\text { MS3 }\end{array}$ & $\begin{array}{l}3.775(4)[14] \\
3.820 \\
3.786\end{array}$ & $\begin{array}{l}4.06[14] \\
4.123 \\
4.095\end{array}$ & $\begin{array}{l}4.31[14] \\
4.390 \\
4.372\end{array}$ & $\begin{array}{l}2.123 \\
2.123 \\
2.123\end{array}$ & $\begin{array}{l}0.076 \\
0.076 \\
0.076\end{array}$ & $\begin{array}{l}12.271(15)[11] \\
12.542 \\
12.336\end{array}$ \\
\hline${ }^{90} \mathrm{Zr}$ & $\begin{array}{l}\exp \\
\text { S3 } \\
\text { MS3 }\end{array}$ & $\begin{array}{l}4.263(8)[14] \\
4.316 \\
4.266\end{array}$ & $\begin{array}{l}4.58[15] \\
4.640 \\
4.593\end{array}$ & $\begin{array}{l}4.81[15] \\
4.914 \\
4.875\end{array}$ & & & \\
\hline${ }^{116} \mathrm{Sn}$ & $\begin{array}{l}\exp \\
\text { S3 } \\
\text { MS3 }\end{array}$ & $\begin{array}{l}4.623[11] \\
4.685 \\
4.628\end{array}$ & $\begin{array}{l}4.96[11] \\
4.997 \\
4.941\end{array}$ & $\begin{array}{l}5.24[11] \\
5.253 \\
5.119\end{array}$ & $\begin{array}{l}2.187 \\
2.187 \\
2.187\end{array}$ & $\begin{array}{l}0.108 \\
0.108 \\
0.108\end{array}$ & $\begin{array}{l}16.620(15)[11] \\
17.002 \\
16.657\end{array}$ \\
\hline${ }^{124} \mathrm{Sn}$ & $\begin{array}{l}\exp \\
\text { S3 } \\
\text { MS3 }\end{array}$ & $\begin{array}{l}4.674[11] \\
4.738 \\
4.680\end{array}$ & $\begin{array}{l}5.00[11] \\
5.048 \\
4.990\end{array}$ & $\begin{array}{l}5.27[11] \\
5.300 \\
5.242\end{array}$ & $\begin{array}{l}2.187 \\
2.187 \\
2.187\end{array}$ & $\begin{array}{l}0.108 \\
0.108 \\
0.108\end{array}$ & $\begin{array}{l}16.934(24)[11] \\
17.329 \\
16.980\end{array}$ \\
\hline
\end{tabular}

\section{Conclusions}

In this work the Skyrme single particle potential has been modified by adding a new term, which is surface peaked but has also an influence in the interior, as seen in Figure 1. However, by constructing the single particle directly, rather than from an interaction we lose the ability to calculate the

[1] D. Vautherin and D. M. Brink, Phys. Rev. C5, 626 (1972).

[2] M. Beiner, H. Flocard, N. Van Giai, and P. Quentin, Nucl. Phys. A 238, 29 (1975).

[3] C. B. Dover and N. Van Giai, Nucl. Phys. A 190, 373 (1972).

[4] B. A. Brown, S. E. Massen, J. I. Esudero, P. E. Hodgson, G. Madurga, and J. Vinas, J. Phys. G: Nucl. Phys. 9, 423 (1983).

[5] H. S. Kohler, Nucl. Phys. A 258, 301 (1976).

[6] S. Krewald, V. Klfm, J. Speth, and A. Faessler, Nucl. Phys. A 281, 166 (1977).

[7] M. Waroquier, J. Sau, K. Heyde, P. Van Isacker, and H. Vincx, Phys. Rev. C 19, 1983 (1979). total binding energy. Nevertheless, the calculation of the expectation value of the new term shows that this term decreases the binding energy of the $48 \leq A \leq 208$ nuclei by about $5 \%$. This work shows that it is possible to correct the Skyrme type interaction so that the charge densities of nuclei go closer to the experimental ones, if we add a suitable surface peaked term.
[8] N. Van Giai and H. Sagawa, Phys. Lett. 106 B, 379 (1981).

[9] H. D. Wohlfahrt, E. B. Shera, M. V. Hoehn, Y. Yamazaki, and R. M. Steffen, Phys. Rev. C23, 533 (1981).

[10] a) C. G. Li, M. R. Yearian, and I. Sick, Phys. Rev. C9, 1861 (1974). b) I. Sick, 1978. Private communication with B. A. Brown.

[11] J. M. Cavedon, PhD Thesis Orsay 1980

[12] H. D. Wohlfahrt, O. Schwentker, G. Fricke, H. G. Anderson, and E. B. Shera, Phys. Rev. C 22, 264 (1980).

[13] B. A. Brown, S. E. Massen, and P. E. Hodgson, J. Phys. G: Nucl. Phys. 5, 1655 (1979).

[14] H. Rothhaas, PhD Thesis Universität Mainz (1976).

[15] J. Decharge, D. Girod, and B. Grammaticos, Nucl. Phys. A 358, 203 c (1981). 